\section{Designing Publicly Engaged First-Year Research Projects} Protest Art and Social Change

\section{Bridget Draxler}

\author{
St. Olaf College (draxler@stolaf.edu)
}

\title{
Reflection: Language and Identity
}

\section{in the Composition Classroom}

My "Research Paper: Protest Art and Social Change" assignment asks students in a first-year writing preparation course to choose a work of protest art related to a particular social justice issue, write a research paper that frames this issue within our community, and then create their own protest art for local distribution as a call to action. The assignment ties together my identities as a literary historian, a public humanist, and a composition teacher in its combination of archival, multimodal, and local research and writing. More importantly, it gives emerging writers multiple ways to express their voices. But I tell students frankly, I am no artist. "If all you can draw is stick people," I say, "that's great. Stick people are all that I can draw, too. I'm interested in what you have to say about those stick people in your writing."

Creating local protest art in my composition classroom is a way for my students to claim agency as writers and civic actors in our community, and my goal as a teacher is to help them to see these emerging identities as powerful and mutually constructive. My task is made easier by the fact that my students are drawn to work that means something to them, and they excel at understanding the complexities of intersectional identities. The particular course in which I teach this assignment at St. Olaf College is a developmental or basic writing course, or what we like to call a first-year writing preparation course. St. Olaf is a private, selective, rural residential liberal arts college of 3,000 students; while we are experiencing rapid demographic changes in our student body (with increasing populations of neurodiverse, international, and multilingual students, for instance), we remain a privileged and predominantly White institution (PWI).

\begin{abstract}
This research assignment invites students in a first-year writing preparation course to explore topics of social justice through protest art. The course is taught at a small, private liberal arts college in a course for "emerging writers." I have taught this assignment at a predominantly White institution (PWI), in a course of protest art from the campus library special collections, frame the social justice issue it addresses in a their own story. Finally, linking public history to civic engagement, students create their own protest art as a community call to action. The multimodal, local, and personal nature of this writing assignment civic actors. This assignment can create space for students to use their multilingual identities to speak for meaningful change.
\end{abstract}

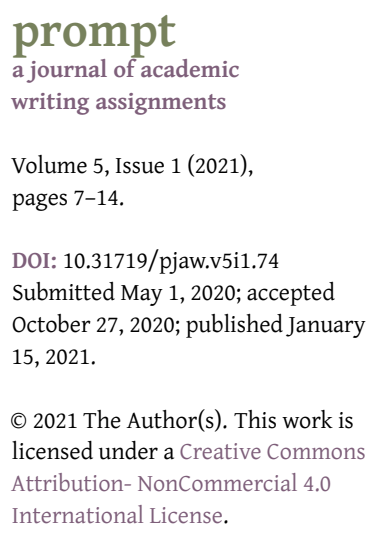

(C) 2021 The Author(s). This work is licensed under a Creative Commons Attribution- NonCommercial 4.0 International License. 
In my course, however, students are almost all low-income, first-generation students of color-which creates both a risk of stigmatization and an opportunity for meaningful community. Alvarez and Lee (2020) remind us that we live in a linguistically pluralistic society in which students bring "rich and complex language practices" (p. 62) to our classrooms that rub against the "monolingual ideology of U.S. education" (p. 62), for which they face "institutional surveillance and policing of their own language practices" (p. 68). In a basic writing course filled with students who are Black, Indigenous, and people of color (BIPOC) at a PWI, the course itself can perpetuate the stigma. As a non-tenure track (NTT) faculty member who teaches basic writing without explicit training in the field (all of the basic writing teachers in my school are NTT), my position within the institutional hierarchy is also marginal. My body can exacerbate my students' feelings of marginality, too: I continually struggle with the ways in which my physical presence, as a White professor at a PWI, shapes the ways in which my students experience the course, and the degree to which they feel comfortable being and expressing themselves. They make assumptions, understandably, about what kind of language I expect from them based on my power, position, and race. For a handful of students, the way I look can become a barrier to their learning. The fact that this course exists, and the fact that I teach it, is evidence of a systemically unjust world.

Yet I am often reminded how the course itself, partly through the demographics of its students and partly through its marginalized status outside general education, becomes a site for us to consider structural inequality within our own institution. My students are, by and large, hungry for opportunities to name, confront, and address these inequities, and while most could be described as "emerging" writers, in terms of their grasp of standardized written English, they carry sophisticated vocabularies and ways of thinking about identity and social justice. $^{1}$

While the nominal purpose of this course seems to be assimilationist-to prepare writers for college-level writing-my real goal is to equip students with the confidence to advocate for themselves as writers, even within a system that may not automatically recognize or reward the ways of knowing and using language in which they thrive. Because the very existence of this course is tied up with stigmatization of language outside standardized written English, and because students are placed into it, it becomes even more imperative to give them opportunities for choice and agency by inviting students to do things like co-create assignment rubrics, opt into labor-based contract grading (Inoue, 2019), and write multimodal projects.

\section{Multimodality and Writing Social Change}

Multimodality is certainly nothing new to composition or human communication; Jody Shipka (2011) writes about the ways in which writing is and always has been multimodal. ${ }^{2}$ But for many students, multimodality does not "count" as college writing the same way that multilingualism does not "count" as college writing. ${ }^{3}$ It is not formal; it is not academic; it is not appropriate. The euphemisms are many, but they all signal a privileging of certain kinds of writing and writers. And crucially, Shipka suggests, destigmatizing one can destigmatize the other.

Multimodality leads to a reconsideration of what works rhetorically rather than what is "right," and a recognition of contexts in which writing effectively may not be strictly "correct." Assigning a multimodal project led to the first time, for instance, that students turned in multilingual writing projects to me. I did not invite them explicitly or even anticipate that they would create multilingual projects, but as Shipka (2011) may have anticipated, the nature of the multimodal assignment gave them permission to do so.

There is also an unexpected way in which assigning a creative, multimodal project, particularly as someone with limited artistic abilities, helps reposition my expertise, and theirs, 
in the classroom. When students see me draw stick people on the board or hear me use my own "home" language, they are primed to realize that I am also not the absolute authority on their artwork, their topic, or their language. They gain confidence in recognizing their own meaningful expertise: choosing topics that draw on their cultural epistemologies and embodied experiences, and writing in language that demonstrates deep understanding of their audiences and themselves.

Integrating art (or, if you want to be more fancy, "craftivism" (Greer, 2014)) into my composition course might seem like an unlikely choice for someone who is intimidated by Play-Doh. But in fact, while it does not represent my skill set, it does capture my philosophy of teaching writing. By challenging students to identify an issue they care about, conduct local research about that topic, and then propose specific local action, I hope students will see their writingand multimodal communication more broadly-as a way to help create a more just world. If they can believe that their writing can actually make a difference, I hope that they will embrace both their responsibility to promote change and their identities as writers, and the ways those roles are mutually constitutive.

\section{Protest Art}

This assignment was a civic engagement project before it was a multimodal one. Teaching publicly engaged research and writing to first-year students is not radical, but it is transformative. While the magnitude of global problems can seem overwhelming and students can feel discouraged in the face of massive systemic injustices, reframing research assignments to focus on local issues, local sources, and local solutions can give students the tools and confidence to make changes they can see. My locally focused research assignment has evolved over the past ten years, sometimes including curation, sometimes in groups, and once as a podcast. The idea to add protest art to my local research assignment came from what may seem like an unlikely source: the campus archives.

Before Minneapolis erupted, just 40 miles north of us, as an important site of Black Lives Matter (BLM) protest in the wake of George Floyd's murder, I set up a meeting with our new Librarian for Special Collections and Archives Instruction to see what local sources students might access in our campus archives. She steered me to a rich collection of Artists' Books, recommending protest art from the Justseeds Artists' Cooperative, a network of artists based in Pittsburgh that is "committed to social, environmental, and political engagement" and that "believe in the transformative power of personal expression in concert with collective action" ("Justseeds | About," n.d., header \& para. 1). The three collections students chose from were "Migration Now!" (2012), a series of prints that frame migration as a human right; "We Are The Storm" (2014), a collection that frames climate change in terms of environmental justice, and the ways marginalized peoples are most severely impacted by fracking, oil pipelines, and mining; and "Celebrate People's History: Iraq Veterans Against the War" (2014), a multimedia portfolio by and about veterans who have spoken out and taken action "to end the wars they served in" (para. 3).

Students visited the St. Olaf Libraries Special Collections to view a curated collection of posters advocating for social justice, and they used these works of art to inspire topics for their locally-driven research project, which culminated in the creation of their own protest art. In developing this version of the assignment, I worked closely with librarians in Special Collections and Research Instruction, who introduced students to our special collections and local online resources along with the more typical popular and peer-reviewed sources. Modeling this collaborative approach to students made them, I think, more open to using a collaborative approach themselves-seeking advice from our librarians, workshopping with peers or the 
embedded Writing and Research Tutors, and reaching out to their home communities. ${ }^{4}$

\section{Assignment Sequence}

Students' first assignment for this project was a Special Collections Poster Analysis Activity, which asked them to choose three prints and respond to the text, design elements, and their own first impressions (see Supplementary Materials). To prepare students to do this analysis, I gave them a basic introduction to visual literacy, drawing on their own experiences as creators and consumers of visual material, but also building on the rhetorical analysis essay they had written earlier in the term. We talked about how visual texts, like written texts, can use stylistic elements like repetition, allusion, humor, organization and voice as rhetorical strategies, but how they also employ color, font, size, perspective, and symbolism to engage their audience. Students translated what they learned about author, purpose, context, and audience to analyzing works of art, and they considered the interplay of text and images in evaluating its rhetorical impact.

The assignment also built on the essay they had written earlier in the term supporting an opinion with personal experience. In this essay, students wrote about a local memorial, contextualized by readings surrounding the debate about removing memorials that glorify confederate or colonial history. This early practice of using personal experience as evidence, and then framing this experience as one of many "source" types for their research paper, set them up to reflect on their own identity, their stake in the issue, and their responsibility to take action.

While the research assignment built on these previous assignments and others, it was the first time that semester I asked students to conclude their essay with a proposal for specific, local change. The call to action, both in the essay and later in their own protest art, shifted students from reflecting and researching to action and activism. Many students found that identifying problems was easier than pitching solutions. It was, I would argue, the most empowering part of the assignment, as students pieced together concrete ways, based on their research and their individual experiences, to confront systemic injustice in their own communities. A Tibetan student who tackled the conflict between Tibet and China, for instance-a conflict that the student felt was deeply personal and impossibly complex-became passionate about educating her peers who were unfamiliar with the history or her perspective on it, including a Chinese student in her writing group. She could not negotiate a productive relationship between China and Tibet, but she did negotiate a productive relationship with her peer. It was not easy for either of them, but they practiced small-scale conflict resolution in a way that confronted this conflict in our classroom community.

Framing this issue locally and identifying a specific local audience helped other students to be specific in their argument and local in their solution. One student, for instance, wrote to first-generation students with immigrant parents about balancing the pressures of school and home. Another wrote to offices on our campus that support LGBTQ students and international students about better supporting the intersectional identities of queer immigrant students. Another challenged their peers' assumptions by explaining how the cultural identity of Latinx immigrants shapes perspectives and attitudes about higher education. One memorable essay written to LGBTQ Hmong youth in the writer's hometown offered support and advice for holding together identities that may sometimes seem conflicting. ${ }^{5}$ In each of these cases, a specific local audience created a sense of urgency, purpose, and humanity in their writing.

Working collaboratively with library staff, special collections staff, writing and research tutors, peers, and me was an important part of this essay process. Cultivating a deeply collaborative writing process helped students to consider multiple points of view more effectively and inclusively. While the assignment asked for a variety of source types-including art from special 
collections, local news sources, popular sources, scholarly reference works, and peer reviewed sources, along with their own personal experiences-one surprise for me was a request from several students to also include personal interviews. After the assignment was amended to include this option for a local source, many chose to interview fellow students, family members, or neighbors to include personal stories about these issues to complement their own. These interviews heightened the personal stakes for many students, as some shared stories of a grandparent who had been a refugee or a peer in the course whom they discovered during peer review to have an immigration story that mirrored their own (see peer review worksheet in Supplementary Materials).

Asking students to create their own protest art fittingly closed this assignment, which started and ended with thinking about ways that multimodal writing can create social change. During the final exam period, students transformed the call to action from their essay into a work of protest art (see final exam prompt in Supplementary Materials). They could collage, paint, marker, or sew. Some wrote their messages in Spanish or Hmong, as appropriate to their chosen audience. Some drew stick people.

To complement their posters, students wrote artists' statements reflecting and rhetorically analyzing their artwork. These statements were the best writing I saw from students all semester. Their intentionality and purpose as artists and writers were striking: one modified the Tibetan flag to replace the snow lions with a silhouette of protesters; another drew a tear on the face of queer youth with the Hmong symbol for family. With an invitation from our campus archives, many students chose to donate their posters and artist statements, so, alongside the robust special collections on protest art, future visitors to our archives will be able to also see and hold the students' protest art.

Near the end of the term, students spent a full class period debating and designing the rubric for their poster and artists' statement (see rubric in Supplementary Materials). While students had been writing for my rubric all term, it was a fitting capstone for the course to give them an opportunity to take ownership by evaluating the quality of their own work.

\section{Future Work}

I could imagine adapting this assignment in a variety of contexts to reflect the particularities of community: working with local artists, maybe even inviting them to visit the course to discuss their inspiration or process; choosing topics that are more narrowly focused to the geographi$\mathrm{cal} /$ cultural/environmental contexts of particular communities; or considering other media, perhaps by having students design their own sculptures to critically explore local memorials, or create digital texts to consider social media and online communities. I could imagine a course like this co-taught with faculty in writing/English and art, or as a more explicit community engagement course working with particular community organizations as co-researchers or audiences for student work. I could imagine students completing the project in small teams rather than individuals to heighten the emphasis on collaboration. I could imagine challenging students to do the work of enacting their own call to action.

In fall 2020, we studied the George Floyd Memorial ${ }^{6}$ and Say Their Names Cemetery ${ }^{7}$ as examples of local protest art. Many of my students are from Minneapolis, and many started college this fall having experienced racialized trauma, and also having participated in protests. This urgency (along with social distancing requirements) shifted our focus from physical artwork in our archives to protest art posted on artists' social media pages in response to the pandemic, the election, and BLM. Artist-activist LMNOPI led a virtual conversation about her process and purpose and the role of protest and art in American democracy. ${ }^{8}$ Students contributed to a visiting policy-driven art installation called "Hostile Terrain 94." Before viewing the 
immigration-themed protest art in our archives, students filled out virtual toe tags, which will be used in the Hostile Terrain 94 exhibit when it opens spring 2021, to commemorate migrants who have died trying to cross the US/Mexico border. ${ }^{9}$ In small groups, we also visited our campus art museum to tour a stunning exhibit by New Orleans artists Chandra McCormick and Keith Calhoun. After their studio flooded during Katrina, they recovered and reframed their moldy, cracked, and waterlogged photographs as abstract art. Both the images themselves and the process of their re-creation are a testament, they argue, to the resiliency of the city's Black community in the wake of Katrina and in the face of new challenges during the pandemic.

The concept of "process" creates a meaningful link between efforts to seek social justice and the process of writing. We are all of us, me included, improving as writers and growing as people, making our words a little bit better and our world a little more just. Reimagining the "standard" college research paper provides a unique opportunity to develop students' sense of local agency, community engagement, creativity, self-expression, and personal authority in pursuit of a more just world, and it helps them see writing as itself an act of social change.

\section{ASSIGNMENT}

\section{Research Paper: Protest Art \& Social Change}

For your final paper, we will be returning to the idea of memorials, if we think about the ways that archives can serve as memorials of people, groups, and events. Like any other memorial, archives are complicated sites of memory and power, where the agency to preserve and tell one's own story is a privilege afforded to the few, but also where our broader cultural memories and values are captured and honored in a meaningful way. More specifically, you will be looking at archival collections on artist activist books, or protest art. These works of art will serve as one of a variety of source types you'll use to make a larger argument about the issue they address.

The goal of this paper is to connect the tasks you've done in essays 1-4 (stating an opinion, analyzing texts, responding to opinions, synthesizing outside research) into a final culminating essay. In this paper, you will be taking a stand on a controversial issue, and use a variety of sources (peer reviewed and popular, primary and secondary, data and art) to support your opinion on that issue.

1. You will begin your essay by telling a story about an issue that brings it locally to St. Olaf College, Northfield, Minnesota, or another "home space" of your choice. What is exciting, resonant, or important about this story to that community? Identify a specific local audience for your paper, convince them of the stakes, and establish your opinion.

2. Then, in the body of your paper, you will broaden the topic, shifting from its local ramifications to national or even international scale. In order to contextualize the issue and support your opinion, you should rely on a variety of rhetorical tools and a variety of types of evidence, including:

a. At least one work of protest art from special collections (note: you will want to research the artist to understand their role and interest in this movement along with the time, place, and audience that contextualizes their work).

b. At least one local, digitized source (St. Olaf College Archives Online, St. Olaf Messenger online, campus yearbooks, local newspaper, etc.; see the course libguide)

c. At least one popular source (magazine, newspaper, etc.) 
d. At least one scholarly reference book

e. At least one peer-reviewed scholarly source

f. Evidence from your own experience

Your argument should synthesize these sources into a scholarly conversation, but put your voice (including your argument and your experience) at the forefront. You may use the synthesis matrix handout to help you.

3. Finally, you will end with a call to action, proposing a specific local action that your audience can take to make a change. The change could be an individual mandate or a community effort, but it should be a specific, local goal that you can demonstrate will be both meaningful and achievable.

As you prepare for this project, we will have library sessions on academic research and archival research. While library research is maybe more strategic and intentional, archival research is maybe more exploratory and serendipitous. You'll need to model skills in both these areas to succeed in this essay. Please take advantage of library staff, including Jillian Sparks and Maggie Epstein, in addition to your writing and research tutor and me, as you gather and interpret sources.

Guidelines: You will be expected to follow a writing process, and I will consider your process in my evaluation. A well-developed essay will be approximately 4-5 pages (1000-1250 words). Your essay should be typed, double spaced, with your name and date at the top. Be sure to include an effective title that highlights the main idea of your argument. Use MLA guidelines for citation. Be sure to double check any auto-generated citations, and use Easy Writer for instructions on unusual source types like a work of art (p. 154) or unpublished work (p. 156).

\section{Acknowledgements}

Thanks to Ann Green, Olivia Giannetta, Maggie Epstein, Jillian Sparks, Diane LeBlanc, Seng Lor, and two anonymous reviewers from Prompt for contributing to the course and/or offering feedback on drafts of this essay. Thank you especially to Jillian Sparks, Librarian for Special Collections and Archives Instruction, and Maggie Epstein, Research and Instruction Librarian, for their invaluable contributions to inspiring and designing this research assignment. I have also been inspired by a number of colleagues at my institution who teach transformative courses in writing: Diane LeBlanc, Becca Richards, Anne Berry, Louis Epstein, and Kaethe Schwehn most especially. Finally, I am indebted to faculty who teach publicly engaged first-year writing courses (captured in the Campus Compact Syllabi Archive ("Syllabi Archive," n.d.) and Project Pericles Course Syllabi ("Course Syllabi," n.d.)) that weave together tutoring, interviewing, and storytelling to empower students to make local change.

\section{Notes}

${ }^{1}$ Of course, we could see this combination not as unexpected, but actually predictable, if we recall Judith Butler's (1999) preface to Gender Trouble, which reminds us that "It would be a mistake to think that received grammar is the best vehicle for expressing radical views, given the constraints that grammar imposes upon thought, indeed, upon the thinkable itself... If gender [or insert your socially-inscribed hierarchy of choice here] itself is naturalized through grammatical norms, as Monique Wittig has argued, then the alteration of gender at the most fundamental epistemic level will be conducted, in part, through contesting the grammar in which gender is given" (p. xix-xx). Thanks to Abby Benusa for steering me to this quote.

${ }^{2}$ While Shipka (2011) embraces the notion of multimodality as "routine," Shipka is eager to separate the broad and inclusive concept of multimodality from modalities that are exclusively technological or "textually overdetermined," in favor of a more process-oriented understanding of the concept. "We must attend," she writes, "to the dynamic, emergent, distributed, historical, and technologically mediated dimensions of composing processes" along with the means and modes of production (p. 14). She advocates for empowering students to choose their own writing goals and 
modalities and to "assume responsibility for evaluating, describing, and sharing with others the purposes and potentials of their work" (p. 16). This idea of asking students to "account" for their "rhetorical objectives and... choices" (p. 16) fits nicely with the final element of my assignment described here, which asks students to create and rhetorically analyze a piece of protest art, though giving students more autonomy in choosing their own modality would better suit Shipka's model.

${ }^{3}$ For excellent work on the interconnectedness of multimodality and multilingualism, see Shipka (2016).

${ }^{4}$ Writing 110 Writing and Research Tutors are cross-trained by me, the writing center director, and a research librarian, and are typically students who have taken Writing 110 themselves.

${ }^{5}$ Minneapolis/St. Paul is one of the largest Hmong communities in the world, as a result of refugee resettlement after the Vietnam War. LGBTQ acceptance in the Hmong community remains low, though I learned from this student that St. Paul has been described as a "gay mecca" for LGBTQ Hmong youth.

${ }^{6}$ This informal community memorial was created at the site in Minneapolis where George Floyd was murdered, and includes murals, a sculpture of a black power fist, signs, flowers, and other ephemera.

${ }^{7}$ Anna Barber and Connor Wright's "Say Their Names Cemetery" is a collection of 100 headstones with the names of African Americans killed by police. The cemetery fills an open park space in Minneapolis near the site of George Floyd's murder; the white rows are reminiscent of Arlington Cemetery but are each marked with a black power fist.

${ }^{8}$ LMNOPI is an American painter, printmaker, and street activist whose portraits and murals highlight leaders of social justice movements ("LMNOPI," n.d.).

${ }^{9}$ Learn more about Hostile Terrain 94 from Gomez (2020) and from "Undocumented Migration Project: Background" (n.d.).

\section{Supplementary Material}

For supplementary material accompanying this paper, including a PDF facsimile of the assignment description formatted as the author(s) presented it to students, please visit https: //doi.org/10.31719/pjaw.v5i1.74.

\section{References}

Alvarez, S. P., \& Lee, E. (2020). Ordinary difference, extraordinary dispositions: Sustaining multilingualism in the writing classroom. In J. W. Lee \& S. Dovchin (Eds.), Translinguistics: Negotiating innovation and ordinariness (pp. 61-72). Routledge.

Butler, J. (1999). Gender trouble. Routledge.

Celebrate people's history: Iraq veterans against the war. (2014). https://justseeds.org/portfolio/celebratepeoples-history-iraq-veterans-against-the-war/

Course syllabi. (n.d.). https://www.projectpericles.org/course-syllabi.html

Gomez, N. (2020). Hostile Terrain 94: Art as a means for political change. http://www.impactmania.com/ $\mathrm{im} /$ hostile-terrain-94-art-as-a-means-for-political-change/

Greer, B. (Ed.). (2014). Craftivism: The art of craft and activism. Arsenal Pulp Press.

Inoue, A. B. (2019). Labor-based grading contracts: Building equity and inclusion in the compassionate writing classroom (1st edition). WAC Clearinghouse.

Justseeds | About. (n.d.). https://justseeds.org/about/

LMNOPI. (n.d.). https://lmnopi.com

Migration now! (2012). https://justseeds.org/portfolio/migration-now/

Shipka, J. (2011). Toward a composition made whole. University of Pittsburgh Press.

Shipka, J. (2016). Transmodality in/and processes of making: Changing dispositions and practice. College English, 78(3), 250-257. http://www.jstor.org/stable/44075115

Syllabi archive. (n.d.). https://compact.org/resource-type/syllabi/

Undocumented migration project: Background. (n.d.). https://www.undocumentedmigrationproject.org/ background 1

We are the storm. (2014). https://justseeds.org/portfolio/we-are-the-storm/ 